\title{
Correction: Accuracy of novel antigen rapid diagnostics for SARS-CoV-2: A living systematic review and meta-analysis
}

\section{The PLOS Medicine Staff}

The third bullet under the "What did the researchers do and find?" section of the Author Summary is incorrect. The publisher apologizes for this error.

The correct text is: Across all meta-analyzed studies, when Ag-RDTs were performed according to manufacturers' recommendations, they showed a sensitivity of $76.3 \%$ (95\% CI $73.1 \%$ to $79.2 \%$ ), with LumiraDx (sensitivity $88.2 \%$ [95\% CI $59.0 \%$ to $97.5 \%$ ]) and, of the instrument-free Ag-RDTs, Standard Q nasal (80.2\% sensitivity [95\% CI 70.3\% to $87.4 \%$ ]) performing best.

\section{Reference}

1. Brümmer LE, Katzenschlager S, Gaeddert M, Erdmann C, Schmitz S, Bota M, et al. (2021) Accuracy of novel antigen rapid diagnostics for SARS-CoV-2: A living systematic review and meta-analysis. PLoS Med 18(8): e1003735. https://doi.org/10.1371/journal.pmed.1003735 PMID: 34383750

\section{G openaccess}

Citation: The PLOS Medicine Staff (2021) Correction: Accuracy of novel antigen rapid diagnostics for SARS-CoV-2: A living systematic review and meta-analysis. PLoS Med 18(10): e1003825. https://doi.org/10.1371/journal. pmed. 1003825

Published: October 13, 2021

Copyright: ๑ 2021 The PLOS Medicine Staff. This is an open access article distributed under the terms of the Creative Commons Attribution License, which permits unrestricted use, distribution, and reproduction in any medium, provided the original author and source are credited. 